\title{
The Extraction of Near-Shore Bathymetry using Sentinel-2A Satellite Imagery: Algorithms and Their Modifications
}

\author{
Abdi Sukmono ${ }^{1}$, Sentanu Aji ${ }^{1}$, Fauzi Janu Amarrohman ${ }^{1}$, \\ Nurhadi Bashit ${ }^{1}$, Lutfi Rangga Saputra ${ }^{2}$ \\ ${ }^{1}$ Department of Geodetic Engineering, Diponegoro University, Semarang, 50275, Central Java, Indonesia \\ ${ }^{2}$ Geospatial Information Agency, Cibinong, West Java, Indonesia
}

\begin{abstract}
Satellite-Derived Bathymetry (SDB) is one of the solution technologies for medium-scale bathymetry mapping in large areas. Various basic algorithms for bathymetry extraction with SDB have been developed. However, they require study and modification for different satellite imageries and different regional characteristics. In this study, the researchers explore three basic SDB algorithms which are often used, namely the Lyzenga algorithm, the Stumpf algorithm, and the Van Hengel \& Spitzer (VHS) algorithm. These three algorithms are modified using the multilinear regression method with the 'average if' function to find out the in-situ depth using Sentinel-2A satellite imagery. These three algorithms can estimate the depth of shallow water bathymetry effectively up to a depth of $20 \mathrm{~m}$. The accuracy test on the extraction results of the modification of the three basic algorithms proves to be able to increase the accuracy of the SDB depth estimation in the depth range of $0-20 \mathrm{~m}$ to an accuracy of $1.888 \mathrm{~m}$ for the Lyzenga algorithm, $2.093 \mathrm{~m}$ for the Stumpf algorithm, and $2.868 \mathrm{~m}$ for the VHS algorithm.
\end{abstract}

Keywords - bathymetry, Sentinel-2A, near-shore, water depth.

DOI: 10.18421/TEM111-17

https://doi.org/10.18421/TEM111-17

Corresponding author: Abdi Sukmono,

Department of Geodetic Engineering, Diponegoro University, Semarang, 50275, Central Java, Indonesia.

Email: abdisukmono@lecturer.undip.ac.id

Received: 04 October 2021.

Revised: 18 January 2022.

Accepted: 24 January 2022.

Published: 28 February 2022.

(c) BY-NC-ND (C) 2022 Abdi Sukmono et al; published by UIKTEN. This work is licensed under the Creative Commons Attribution-NonCommercial-NoDerivs 4.0 License.

The article is published with Open Access at www.temjournal.com

\section{Introduction}

Coastal areas possess a highly important role in economic development for maritime countries. These areas have biological biodiversity and abundant economic activity so that they may serve as an economic booster [1]. The management of activities and development planning in coastal areas needs the support of good spatial data. One of the most important spatial data is near-shore bathymetry data. Bathymetry is important information about water depth and underwater topography [2]. According to Manessa et al., bathymetry data is important for ship traffic, conservation, coastal zoning, and other environmental issues [3].

In general, bathymetry maps are generated by a series of hydrographic surveys starting from tidal surveys to generalization using a single-beam echosounder or multi-beam echosounder mounted on a survey vessel to produce sea depth data. This method can generate very accurate bathymetry estimates, especially in clear seawater [4]. In addition, there is also an Airborne Lidar Bathymetry (ALB) technology. It can also measure sea depth effectively in the coastal zone [5]. However, both methods require quite expensive costs and are timeconsuming for a large area. Frankly, maritime countries need to update their bathymetry maps regularly. Therefore, this is a challenge, especially for maritime countries that have long coastlines, such as Canada, Indonesia, Denmark, Russia, and the Philippines.

Remote sensing technology can be used as an alternative to obtaining bathymetry data, especially for shallow water [6]. This technique/method is known as Satellite-Derived Bathymetry (SDB). SDB can provide an opportunity to perform bathymetry mapping quickly, effectively, and efficiently [7]. In addition to the advantages already mentioned, SDB is also a method that does not require high costs in its operation to obtain water depth data over a large area 
[8]. However, bathymetry mapping using SDB also has weaknesses, namely, it can only map shallow waters (shallow water depth) and the accuracy obtained is still on a medium scale. Despite that, this will be very helpful for the management of coastal areas which have shallow waters, cover large areas, and require periodic updating of bathymetry data.

Several algorithms for processing satellite-derived bathymetry using optical imageries have been developed. Three basic algorithms are widely used as references, namely the Lyzenga algorithm (2006) [9], Stumpf algorithm (2003) [10], and the Van Hengel \& Spitzer algorithm (1991) [11]. To improve the accuracy of the bathymetry extraction results, several researchers modified the three algorithms. In addition, with different imagery input data and different regional characteristics, modifications are needed to obtain good accuracy. This is as has been done by [3] and [6]. They modified the Lyzenga (2006) algorithm and several other basic algorithms on SPOT imagery through linear regression on insitu data. Furthermore, [12] and [13] studied the Lyzenga algorithm (2006) and Stumpf algorithm (2003) on Landsat-8 Imagery for bathymetry estimation in shallow waters by comparing in-situ measurement data and LIDAR measurement data. Several developments of the basic SDB algorithms on imageries, specifically in tropical areas like Indonesia, have also been carried out. [14] conducted a study to evaluate the accuracy of sea depth extraction using the Lyzenga method and its modification using SPOT-7 imagery in Belangbelang Bay, Mamuju. In addition, [15] examined the bathymetry estimation from SPOT-7 imagery in the waters of West Nusa Tenggara using the multiple linear regression (MLR) method. Besides, [16] also examined the comparison of field bathymetry data and Landsat 8 OLI imagery in the Lepar Strait, South Bangka using rationing, thresholding, and mean value approaches. Furthermore, [17] examined Landsat 8 imagery for shallow water bathymetry estimates using the Stumpf algorithm. Several previous studies of the SDB algorithms on multispectral-medium resolution imageries (SPOT and Landsat 8) have been studied quite often. However, studies of the basic SDB algorithms and their modifications on Sentinel-2A imagery to improve its accuracy are still rarely carried out, especially in tropical water areas, such as Indonesia. Sentinel-2A is passive sensor imagery that can be used for processing satellite-derived bathymetry. This imagery is an image that can be downloaded for free and has a fairly good spatial resolution. The spatial resolution offered by the Sentinel-2A imagery is up to 10 meters. This resolution is better than Landsat 8 which has a spatial resolution of only up to 30 meters. For this reason, the objective of this article is to examine the use of the basic SDB algorithms and their modifications on Sentinel-2A imagery in shallow water so that we can determine the depth estimation ability of the algorithm and can improve its accuracy.

\section{Materials and Methods}

\subsection{Research Location and Data}

The research location in this study covered the waters of Malahayati Port, Aceh Province, Indonesia. According to a study conducted by Sitepu et al., the waters in this area have an average current velocity of $0.04 \mathrm{~m} / \mathrm{s}$, making it being classified as having a weak current [18]. The study also revealed that the current caused by the non-tidal factors is greater than the current caused by the tide. For its characteristics, these waters have three sedimentary units, namely sand, silty sand, and sand-silt-clay. Furthermore, the characteristics of sediments in these waters are dominated by sand. Sand in these waters has a percentage ranging from $44.91 \%$ to $95.40 \%$. Meanwhile, the percentage of silty sand is ranging from $4.06 \%$ to $46.50 \%$. Furthermore, the percentage of sand-silt-clay is only ranging from $0.20 \%$ to $28.07 \%$. From these characteristics, it can be concluded that these waters are waters that have clear water conditions, making them suitable for conducting satellite-derived bathymetry research. The following is an overview of the research location obtained through Google Earth (Figure 1). In the figure, a light blue square indicates the research location.

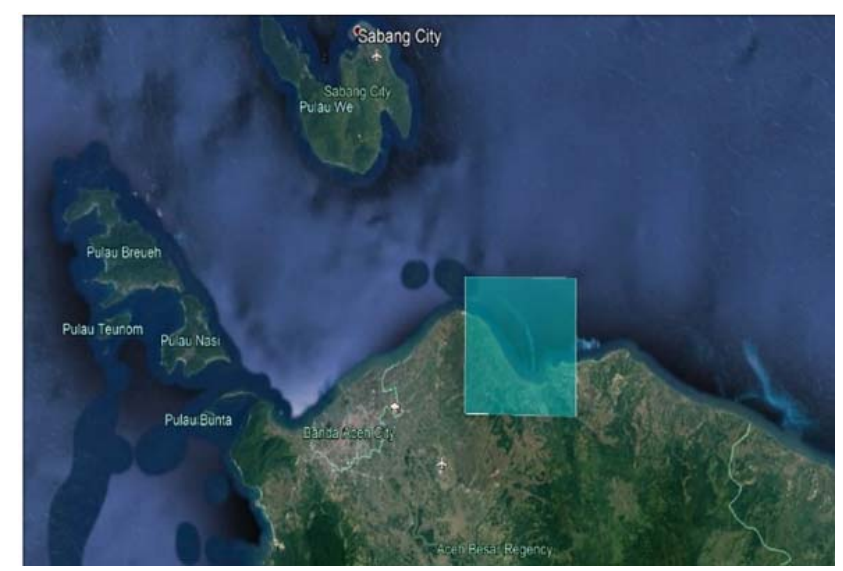

Figure 1. Research Location (Waters of Malayayati Port, Aceh Province, Indonesia)

At the research location shown in Figure 1, the collected data for being used in this study are as follows:

1. Sentinel-2A imagery that was recorded on 22 October 2018 and downloaded for free on the website https://scihub.copernicus.eu. 
2. Bathymetry data or water depth data from a hydrographic survey, using multibeam echosounder in the waters of Malahayati Port, Aceh Besar Regency, Aceh Province, Indonesia, in 2018. The tidal errors on data have been reduced by Indonesia's Geospatial Information Agency (Indonesian: Badan Informasi Geospasial (BIG)), as the in-situ comparison data.

3. Topographical map used for geometric correction of Sentinel-2A imagery.

\subsection{Methods}

\subsubsection{Tidal Correction}

In-situ water depth measurement data from echosounder and SDB data from Sentinel-2A imagery are still influenced by tidal waves. Therefore, it is necessary to convert the measured sea depth to a zero value of the mean sea level (MSL). This was carried out by calibrating both tidal data at the study site to zero MSL. Tidal data were obtained from tidal stations of Indonesia's Geospatial Information Agency.

\subsubsection{Imagery Preprocessing}

The Sentinel 2A imagery used in this study was going through imagery preprocessing consisting of radiometric correction and geometric correction. The obtained Sentinel-2A imagery was level 1C, which was still in the form of ToA (Top of Atmosphere) which needed radiometric/atmospheric correction to become level 2A, namely BoA (Bottom of Atmosphere), and to make the pixel value in the form of reflectance so that the next algorithm operation can be performed. The radiometric correction in this study was performed using the QGIS 3.4.2 application. This correction used the Semi-Automatic Classification Plugin available in QGIS and the Dark of Subtraction method. After the imagery had been radiometrically corrected, the next step was geometric correction. It aimed to correct positional errors in Sentinel-2A imagery. In this study, the Earth Map (Indonesian: Peta Rupa Bumi (RBI)) of Indonesia is on a scale of $1: 25,000$. It was used as a reference for the geometric correction process. Furthermore, the applied transformation method was the first-order polynomial method with a maximum RMSE requirement of 1 pixel.

\subsubsection{Satellite-Derived Bathymetry Processing}

3 basic SDB algorithms were examined in this study, namely the Lyzenga algorithm, the Stumpf algorithm, and the Van Hengel and Spitzer (VHS) algorithm. These three algorithms are basic algorithms that are quite familiar to use in estimating the depth of shallow sea waters.

\section{a) Lyzenga Algorithm}

The Lyzenga algorithm is an algorithm invented by David R. Lyzenga, Norman P. Malinas, and Fred J. Trans through their research conducted in 2006. It is named the Lyzenga algorithm because the research is a development of research that has been carried out by Lyzenga previously in 1978 and 1981. The Lyzenga algorithm (2006) is a simple algorithm method that can estimate the water depth from the data source, namely multispectral images or optical images. The methodology of this algorithm is based on a physical model to determine the reflection of shallow water. The following is equation 1 which describes the Lyzenga algorithm.

$Z=a_{0}+\sum_{i-1}^{N} a_{i} \ln \left(R\left(\lambda_{i}\right)-R_{\infty}\left(\lambda_{i}\right)\right)$

Where:
$\mathrm{Z}$
: Depth of the waters
$a_{i}(i=0,1, \ldots, N):$ Constant coefficient, $\mathrm{N}$ is the
$R\left(\lambda_{i}\right)$ number of spectrum bands

\section{$R_{\infty}\left(\lambda_{i}\right)$}
: Reflectance after atmospheric correction for the spectrum band $\lambda_{i}$
: Average sea depth reflectance in the spectrum band $\lambda_{i}$

\section{b) Stumpf Algorithm}

The Stumpf algorithm was developed by Stumpf (2003) by using the principle of absorption by multispectral bands in water bodies that have differences in which this difference conceptually will produce a ratio between multispectral bands. The ratio between these multispectral bands will change when the water depth changes as well. This algorithm can generate depth data for shallow water. The following is equation 2 which describes the Stumpf algorithm.

$Z=m_{1} \cdot \frac{\ln \left(R\left(\lambda_{B}\right)\right)}{\ln \left(R\left(\lambda_{G}\right)\right)}-m_{0}$

Where:

\begin{tabular}{|c|c|}
\hline$Z$ & : Depth of the waters \\
\hline$m_{1}, m_{0}$ & $\begin{array}{l}\text { : The model constant-coefficient for the } \\
\text { extract of the depth value }\end{array}$ \\
\hline$R\left(\lambda_{B}\right)$ & The reflectance of the blue band \\
\hline$R\left(\lambda_{G}\right)$ & The reflectance of the green band \\
\hline
\end{tabular}

\section{c) Van Hengel \& Spitzer Algorithm}

The Van Hengel \& Spitzer algorithm was developed by W. Van Hengel and D. Spitzer in their study conducted in 1991. This algorithm uses imagery data as a data source to generate bathymetry 
data. This algorithm uses red, green, and blue bands (bands 4, 3, and 2) in its processing. In this algorithm, the parameters $r, s, U r$, and $U s$ are calculated before operating the algorithm. The following is an equation that describes the Van Hengel \& Spitzer algorithm.

$$
\begin{aligned}
& U r=\frac{\operatorname{Var} X 3+\operatorname{Var} X 2}{2 \operatorname{Cov} X 2 X 3} \\
& U s=\frac{\operatorname{Var} X 4+\operatorname{Var} X 2}{2 \operatorname{Cov} X 2 X 4} \text {. } \\
& r=\arctan \left(U r+\sqrt{U r^{2}+1}\right) \\
& s=\arctan \left(U s+\sqrt{U s^{2}+1}\right) \\
& Y 1=[\cos (r) \sin (s) X 2]+[\sin (r) \cos (s) X 3]+ \\
& {[\sin (s) X 4]}
\end{aligned}
$$

\section{Where:}

$\begin{array}{ll}\text { Ur and Us } & : \text { Parameters for calculating } r \text { and } \\ r \text { and } s & \begin{array}{l}\text { : Parameter (rotation angle value) } \\ \text { for calculating the depth index }\end{array} \\ & \text { value } \\ \text { Var X2 } & \text { : Variance for band 2 (blue) } \\ \text { Var X3 } & \text { : Variance for band 3 (green) } \\ \text { Var X4 } & \text { : Variance for band 4 (red) } \\ \text { Cov X2 X3 } & \text { : Covariance for bands 2 and 3 } \\ \text { Cov X2 X4 } & \text { : Covariance for bands 2 and 4 } \\ Y 1 & \text { : Relative depth }\end{array}$

\subsubsection{Algorithm Modification}

This modification aims to improve the accuracy of the depth value obtained from the extraction of SDB. In optimizing the modification of the three basic algorithms examined in this study, the researchers used the multilinear regression (MLR) method. This was carried out by regressing the in-situ depth values (Y) with the depth values extracted from SDB (X) to gain the best relationship model equation.

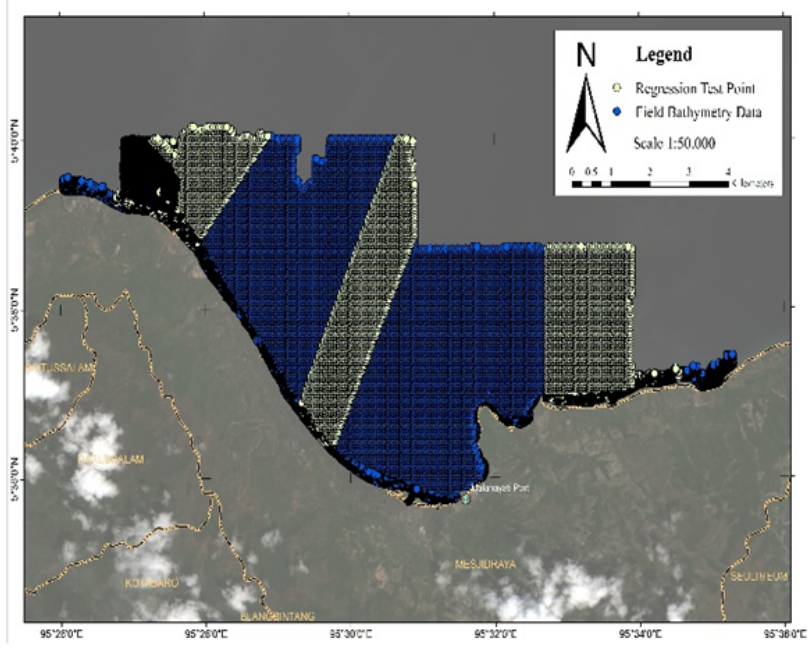

Figure 2. Distribution of in-situ depth points from the results of echosounder measurement to be regressed with the estimated depth of the SDB algorithms
The regression process in this study consisted of two main stages. The first was a regression to get the value of depth of extinction which shows the maximum capacity value of these SDB algorithms in measuring sea depth. Furthermore, it provides a reference to whether the SDB algorithms can only be optimally utilized at the value of the depth of extinction. At this stage, the regression of the in-situ depth points as shown in Figure 2 was carried out using the depth value obtained from the results of the extraction using the basic SDB algorithms. In addition, the number of the regressed in-situ depth points was 34,649 points with the depth value of the waters ranging from $1.98 \mathrm{~m}$ to $335.27 \mathrm{~m}$. Furthermore, after the value of depth of extinction was obtained, in the second regression stage, the value was regressed only to this depth limit. Therefore, from the modification of the three basic algorithms, the optimum model value was obtained at a certain depth limit according to the value of depth of extinction. To optimize the results of the relationship model obtained in the second regression stage, MLR was used with a mean value approach and an 'average if' function for each depth point. The 'average if' function was used to calculate the average of independent data that have the same dependent value to minimize redundant data that may cause bias in the regression process.

\subsection{Accuracy Test}

The accuracy test was carried out by calculating the root mean square error (RMSE) value from independent in-situ depth data that was not included in the algorithm modification process. The accuracy test points used were 7,443 points spread over the research location and had varying depths in the range of the depth of extinction. Furthermore, the RMSE equation is described in equation 8 , as follows.

$R M S E=\sqrt{\sum_{i=1}^{n} \frac{(h i-h a)^{2}}{n}}$

Where:

hi : in-situ depth

ha: extraction depth from Sentinel-2A using the SDB algorithms

$n:$ the number of samples

\section{Results and Discussion}

\subsection{Depth of Extinction}

The processing of the depth of extinction aims to obtain the maximum capability of the basic SDB algorithm in estimating the bathymetry depth of the waters. The value of the depth of extinction can be 
obtained by regressing the in-situ depth points of the echosounder measurement results and the estimated value of the bathymetry depth from the SDB algorithms. The results then generate graphs and model equations, in which the value of the graph point of the model equation that is not linear and has a large deviation is considered to be the limit point of the depth of extinction. Furthermore, the results of the depth of extinction of the three basic SDB algorithms can be seen in Figure 3.

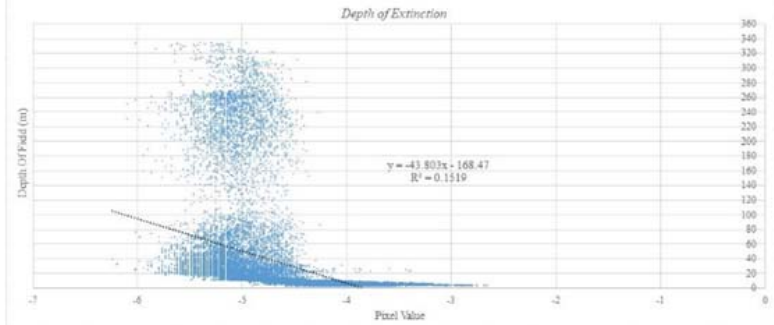

(a)

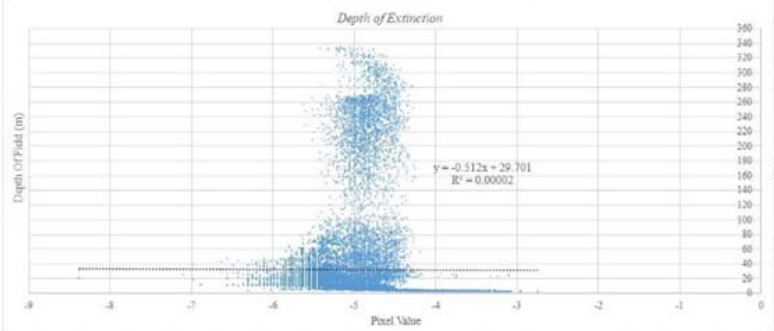

(c)

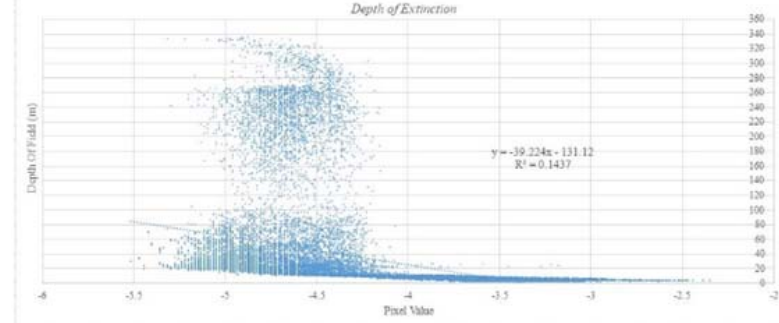

(b)

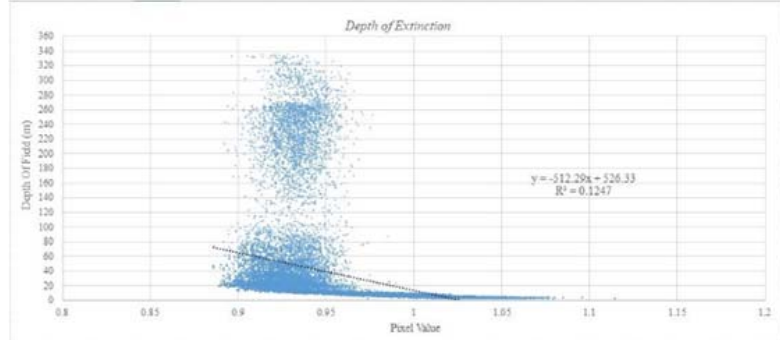

(d)

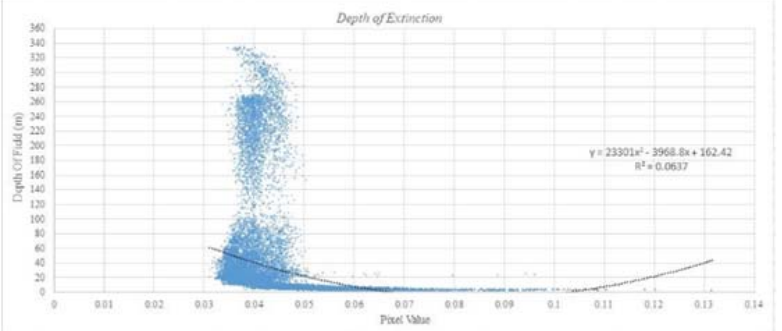

(e)

Figure 3. Graph of the in-situ depth of echosounder measurement results against the estimated depth of the SDB algorithms ((a) Lyzenga algorithm for the blue band, (b) Lyzenga algorithm for the green band, (c) Lyzenga algorithm for the red band, (d) Stumpf algorithm, and (e) Van Hengel \& Spitzer algorithm) for determining the value of the depth of extinction

Based on the regression graph presented in Figure 3 , we obtained the most optimum regression value between the estimated depth value of the SDB algorithms and the in-situ depth, which was up to a depth of 20 meters. This was due to the level of data linearity between the relative depth data generated by the three basic algorithms and good sea depth data which was up to a depth of 20 meters, in which a depth of more than 20 meters may present poor linearity. This value is referred to as the depth of extinction limit. This means that the ability of the three basic SDB algorithms on Sentinel-2A imagery can only optimally estimate the depth of marine waters to a depth of $20 \mathrm{~m}$. At a depth of more than 20 $\mathrm{m}$, the three SDB algorithms will not be effective.

\subsection{SDB Algorithm Modifications using MLR}

Modification of the basic SDB algorithm aims to improve the accuracy of sea depth estimation. Conditions or characteristics of different regions and satellite imageries require adjustments through algorithm modification. This is carried out by continuing the regression in the processing of depth of extinction, wherein the data will be regressed only to a depth of 20 meters. This aims to analyze the regression generated by the two data without interference from data that has poor linearity (i.e., data that exceeds a depth of 20 meters) so that the results of this modified algorithm are only effective for estimating the maximum sea depth to a depth of 20 meters. Furthermore, the results of the modification of the three basic SDB algorithms can be seen in Figure 4 and Table 1. 


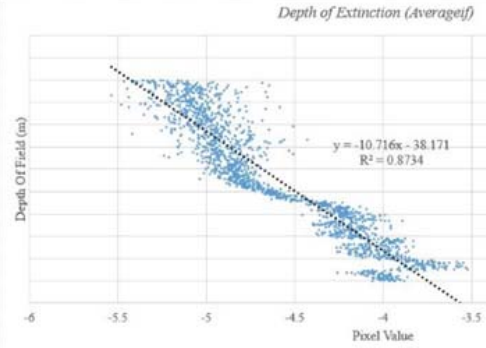

(a)

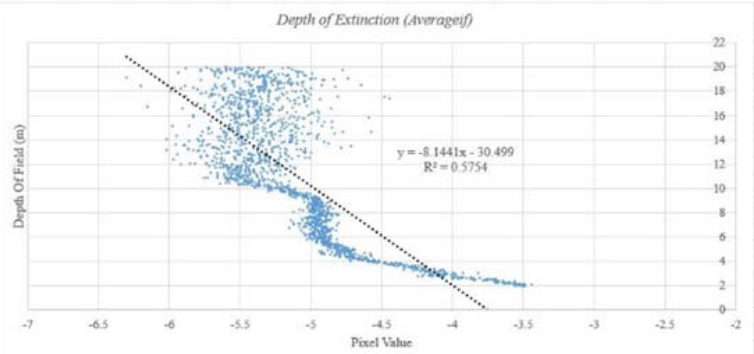

(c)

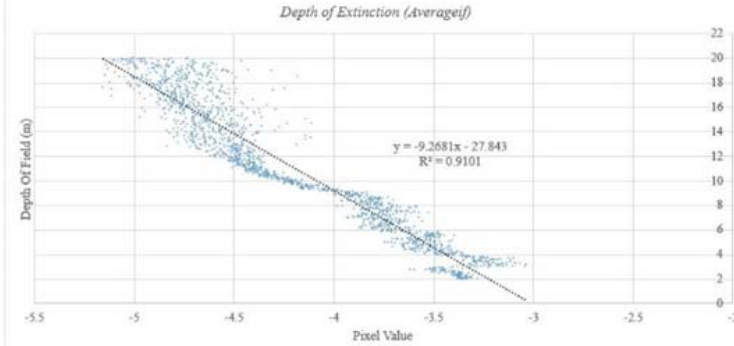

(b)

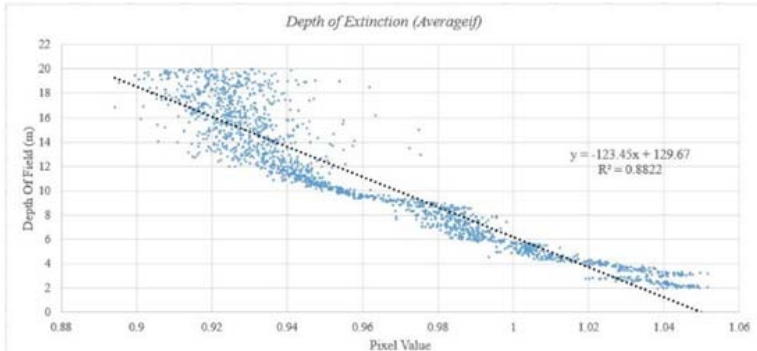

(d)

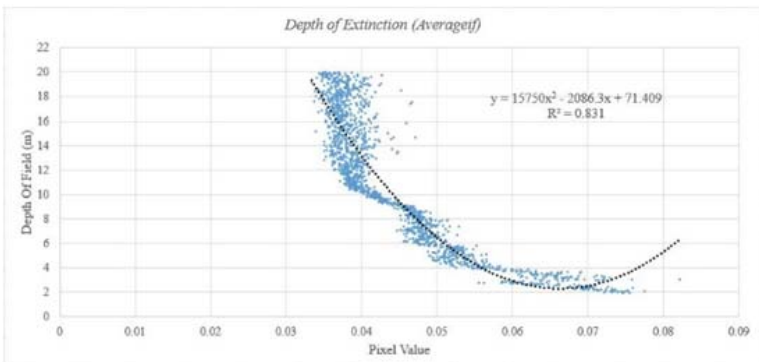

(e)

Figure 4. In-situ depth regression results and depth estimation from results of SDB algorithms on Sentinel-2A imagery ((a) Lyzenga algorithm for the blue band, (b) Lyzenga algorithm for the green band, (c) Lyzenga algorithm for the red band, (d) Stumpf algorithm, and (e) Van Hengel \& Spitzer algorithm) at the limit of the depth of extinction (20 m)

Furthermore, the results of regression presented in Figure 4 are summarized in Table 1. Figure 4 and Table 1 indicate that all the results of the regression have a coefficient of determination greater than 0.5 , in which this coefficient is used to assess the goodness of fit in the linear regression model [19]. According to Moore et al., the value of the coefficient of determination which is $>0.5$ indicates that the resulting regression equation may produce a good relationship model between the dependent variable (in-situ sea depth) and the independent variable (depth estimation based on the results of the basic SDB algorithms on Sentinel-2A imagery) [20]. Therefore, the resulting equation can be used as a modification to estimate the in-situ depth through utilizing the basic SDB algorithms on Sentinel-2A imagery.

Table 1. Summary of the results of the in-situ depth regression calculation and the depth estimation from the results of the SDB algorithms on the Sentinel-2 imagery

\begin{tabular}{|l|c|c|c|}
\hline \multicolumn{1}{|c|}{ Variable $\mathbf{x}$} & Equation & $\boldsymbol{R}^{\mathbf{2}}$ value & Standard error \\
\hline Lyzenga algorithm for the blue band (band 02) & $\mathrm{y}=-10.716 \mathrm{x}-38.171$ & 0.873 & 1.860 \\
\hline $\begin{array}{l}\text { Lyzenga algorithm for the green band (band } \\
\text { 03) }\end{array}$ & $\mathrm{y}=-9.2681 \mathrm{x}-27.843$ & 0.910 & 1.567 \\
\hline Lyzenga algorithm for the red band (band 04) & $\mathrm{y}=-8.1441 \mathrm{x}-30.499$ & 0.575 & 3.407 \\
\hline $\begin{array}{l}\text { Lyzenga algorithm for the combination of } \\
\text { bands 2-3-4 }\end{array}$ & $\begin{array}{c}\mathrm{y}=4.613 \mathrm{X} 1-14,727 \mathrm{X} 2+2.091 \\
\mathrm{X} 3-18.916\end{array}$ & 0.923 & 1.456 \\
\hline Stumpf algorithm & $\mathrm{y}=-123.45 \mathrm{x}+129.67$ & 0.882 & 1,795 \\
\hline Van Hengel \& Spitzer algorithm & $\mathrm{y}=15750 \mathrm{x}^{2}-2086.3 \mathrm{x}+71.409$ & 0.831 & 2.150 \\
\hline
\end{tabular}




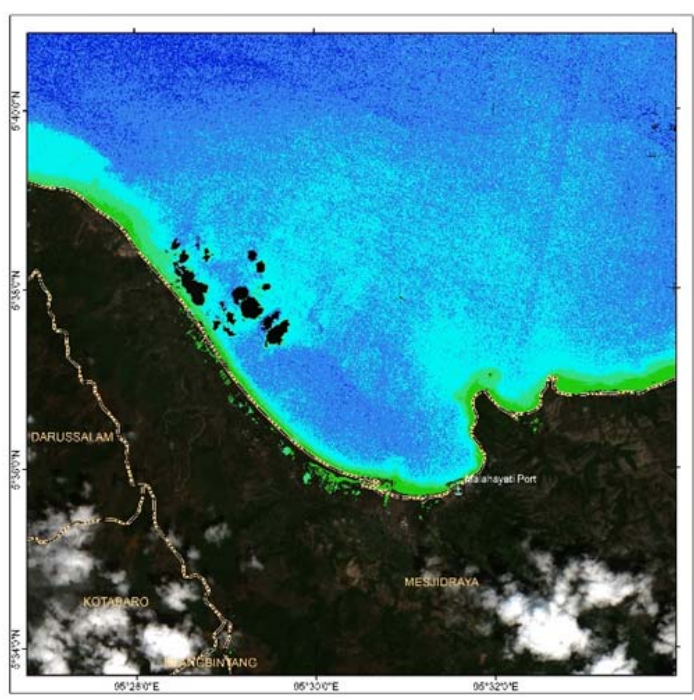

(a)

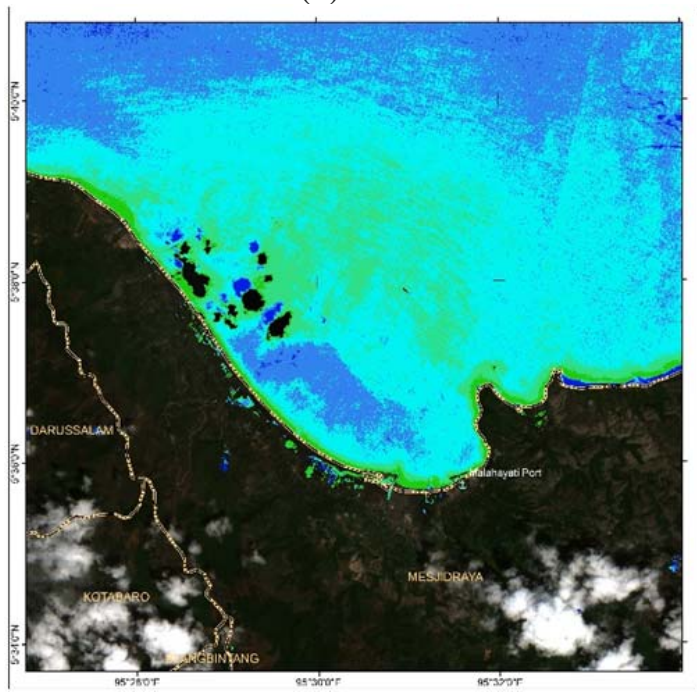

(c)

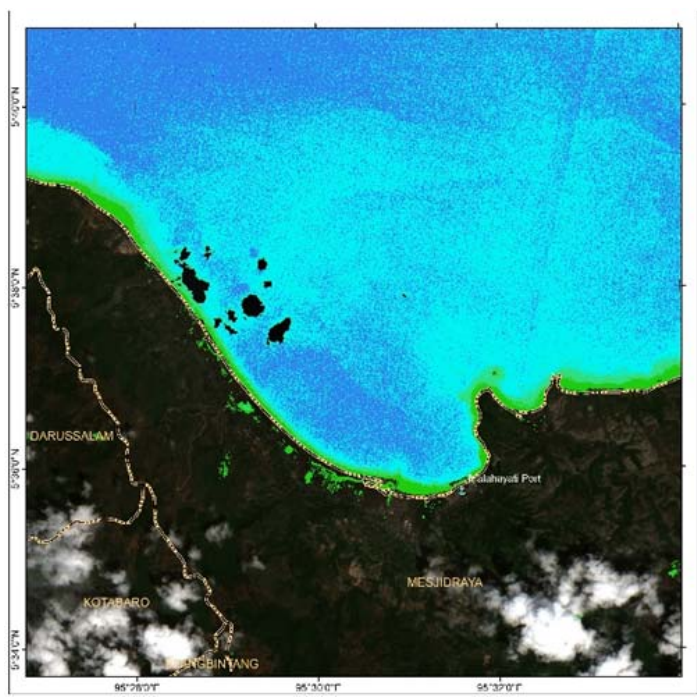

(b)

\begin{tabular}{|c|c|}
\hline & LEGEND \\
\hline$\odot$ & Malahayati Port \\
\hline - & Sub-District Boundary of Aceh Besar District \\
\hline & Depth of $0-5$ meters \\
\hline & Depth of $5-10$ meters \\
\hline & Depth $10-15$ meters \\
\hline & Depth $15-20$ meters \\
\hline & Depth more than 20 meters \\
\hline
\end{tabular}

Figure 5. Results of extraction of bathymetry depth from the modification of (a) the Lyzenga algorithm, (b) Stumpf algorithm, and (c) VHS algorithm on Sentinel-2A imagery

The results of regression presented in Table 1 show that the best relationship model is obtained from the Lyzenga algorithm with a combination between bands 2-3-4 and a coefficient of determination $\left(R^{2}\right)$ of 0.923 . This value indicates a very good model equation relationship, which means that $92.3 \%$ of the independent variable (depth estimation based on the results of the basic SDB algorithms on Sentinel-2A imagery) can define the dependent variable (in-situ sea depth). Overall, the three basic SDB algorithms (Lyzenga algorithm, Stumpf algorithm, and VHS algorithm) can produce modified equations through regression with a coefficient of determination above 0.75 . Therefore, the three modified equations in Table 1 can be used as modifications to improve the sea depth estimation accuracy through estimation based on the results of the basic SDB algorithms on Sentinel-2A imagery.

\subsection{Depth of Extraction}

The results of the regression equation presented in Table 1 are used as a modification of the estimation of the SDB algorithm through the three basic algorithms. Furthermore, based on these equations, the sea depth extraction in the waters of the research location (Malahayati Port, Aceh) was carried out by examining Sentinel-2A imagery. The limit of the extraction capability from the results of this modified equation is at a depth of extinction (less than $20 \mathrm{~m}$ ). At depths greater than $20 \mathrm{~m}$, the estimated value will have a large error. The results of the extraction of shallow sea depths in the research location can be shown in Figure 5.

The results of the extraction of sea depth using the three modifications of the basic algorithm presented in Figure 5 show that, at the estimated depth limit of $<20 \mathrm{~m}$, the results of the Lyzenga algorithm (a) and the Stumpf algorithm (b) have a similar pattern. 
Table 2. Results of the accuracy test on the three basic SDB algorithm modifications

\begin{tabular}{|l|c|c|c|}
\hline \multirow{2}{*}{\multicolumn{1}{|c|}{ Parameters }} & \multicolumn{3}{c|}{ RMSE (meter) } \\
\cline { 2 - 4 } & $\begin{array}{c}\text { Lyzenga } \\
\text { algorithm }\end{array}$ & $\begin{array}{c}\text { Stumpf } \\
\text { algorithm }\end{array}$ & $\begin{array}{c}\text { VHS } \\
\text { algorithm }\end{array}$ \\
\hline$R^{2}$ value & 0.923 & 0.882 & 0.831 \\
\hline Depth accuracy for 0 - 20 meters & 1.888 & 2.093 & 2.868 \\
\hline Depth accuracy for 0 - 5 meters & 1.777 & 1.571 & 2.945 \\
\hline Depth accuracy for 5 - 10 meters & 1.797 & 2.279 & 2.796 \\
\hline Depth accuracy for 10 - 15 meters & 1.466 & 1.923 & 1.749 \\
\hline Depth accuracy for 15 - 20 meters & 3.092 & 3.441 & 4.246 \\
\hline
\end{tabular}

Meanwhile, the result from the Van Hengel \& Spitzer (VHS) algorithm is slightly different in the spatial distribution of $15-20 \mathrm{~m}$ depth. This value can be caused by the results of the regression of the Lyzenga algorithm and the Stumpf algorithm which have a stable linear equation and the better value of the coefficient of determination (0.92 and 0.88). Meanwhile, in the result of regression of the VHS algorithm (c) shown in Figure 5, the error pattern on the regression line at the depth of $>15$ is increasing or moving away from the fit line of the regression equation. To analyze the accuracy of the extraction of these three algorithms, a further test should be carried out.

\subsection{Results of the Accuracy Test}

The accuracy test is needed to ensure the accuracy of the modified model of the three basic SDB algorithms in estimating the sea depth or bathymetry using Sentinel-2A imagery. This test uses 7443 points with varying depths $(0-20 \mathrm{~m})$ and spreading over the research location. The distribution of accuracy test points can be seen in Figure 6.

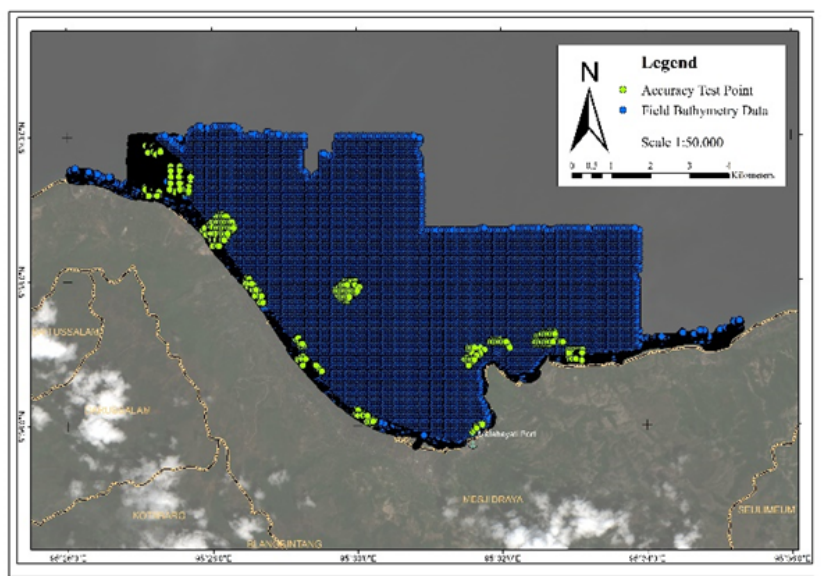

Figure 6. Spatial distribution of the accuracy test points of the results of depth estimation using the modified SDB algorithms

In this accuracy test, the researchers calculated the root mean square error (RMSE) value according to equation 1 utilizing 7,443 test points. Results of the accuracy test were calculated as a whole in the depth range of $1-20 \mathrm{~m}$. They were then also described in each 5-meters depth range to provide detailed accuracy per depth class. Results of the accuracy test are presented in Table 2.

Results of the accuracy test presented in Table 2 show that, at a depth of $0-20$ meters or the entire depth where the accuracy test is carried out, the Lyzenga algorithm has a better bathymetry accuracy, namely 1.888 meters. Meanwhile, the Stumpf algorithm has a bathymetry accuracy of 2.093 meters and the VHS algorithm has a bathymetry accuracy of $2.868 \mathrm{~m}$. These algorithm modifications can increase the accuracy of bathymetry sea depth estimation in shallow water because, in a study by Arya et al. using the Lyzenga algorithm, the accuracy at a depth of $0-$ $20 \mathrm{~m}$ is $2.7 \mathrm{~m}$ [14]. In this study, the modification can increase the accuracy up to $1.888 \mathrm{~m}$.

In detail for per class depth (per 5 meters), the modified Lyzenga algorithm also has the best accuracy against other algorithm modifications in almost all classes, namely $1.797 \mathrm{~m}$ at a depth of 5 10 meters, $1.466 \mathrm{~m}$ at a depth of $10-15$ meters, and $3.0902 \mathrm{~m}$ at a depth of $15-20$ meters. However, in the depth class of $0-5$ meters, the Stumpf algorithm has better accuracy than the Lyzenga algorithm and the VHS algorithm. Therefore, it can be concluded that, overall, the modified algorithm of the Lyzenga algorithm has the best accuracy than the modification of the other two algorithms. Despite that, in the very shallow depth class $(0-5$ meters $)$ the modification of the Stumpf algorithm has better accuracy.

\section{Conclusion}

The three basic SDB algorithms on the sentinel-2A imagery can estimate the depth of the bathymetry up to a depth limit of $20 \mathrm{~m}$. Modification of those three algorithms through MLR regression towards in-situ depth using the 'average if' function can increase the accuracy of the SDB depth estimation in the depth range of $0-20$ meters to an accuracy of $1.888 \mathrm{~m}$ for the Lyzenga algorithm, $2.093 \mathrm{~m}$ for the Stumpf algorithm, and $2.868 \mathrm{~m}$ for the Van Hengel \& Spitzer (VHS) algorithm. 


\section{References}

[1]. Saeed, R., Abdelrahman, S. M., \& Negm, A. (2021). Satellite-Derived Bathymetry Using Landsat-8 Imagery For Safaga Coastal Zone, Egypt. Acta Marisiensis. Seria Technologica., 18(1). https://doi.org/10.2478/amset-2021-0002

[2]. Setiawan, K. T., Suwargana, N., Ginting, D. N. B., Manessa, M. D. M., Anggraini, N., Adawiah, S. W., ... \& Supardjo, A. H. (2019). Bathymetry extraction from spot 7 satellite imagery using random forest methods. International Journal of Remote Sensing and Earth Sciences (IJReSES), 16(1), 23-30. http://dx.doi.org/10.30536/j.ijreses.2019.v16.a3085

[3]. Manessa, M. D. M., Haidar, M., Hartuti, M., \& Kresnawati, D. K. (2018). Determination of the best methodology for bathymetry mapping using SPOT 6 imagery: A study of 12 empirical algorithms. International Journal of Remote Sensing and Earth Sciences (IJReSES), 14(2), 127-136. http://dx.doi.org/10.30536/j.ijreses.2017.v14.a2827

[4]. Pushparaj, J., \& Hegde, A. V. (2017). Estimation of bathymetry along the coast of Mangaluru using Landsat-8 imagery. The International Journal of Ocean and Climate Systems, 8(2), 71-83. https://doi.org/10.1177/1759313116679672

[5]. Pratomo, D. G., \& Putranto, B. F. E. (2019, November). Analysis of the green light penetration from Airborne LiDAR Bathymetry in Shallow Water Area. In IOP Conference Series: Earth and Environmental Science (Vol. 389, No. 1, p. 012003). IOP Publishing. https://doi.org/10.1088/1755-1315/389/1/012003

[6]. Kanno, A., Koibuchi, Y., \& Isobe, M. (2011). Shallow water bathymetry from multispectral satellite images: Extensions of Lyzenga's method for improving accuracy. Coastal Engineering Journal, 53(04), 431-450. https://doi.org/10.1142/S057856341 1002410

[7]. Cahalane, C., Magee, A., Monteys, X., Casal, G., Hanafin, J., \& Harris, P. (2019). A comparison of Landsat 8, RapidEye and Pleiades products for improving empirical predictions of satellite-derived bathymetry. Remote sensing of environment, 233, 111414. https://doi.org/10.1016/j.rse.2019.111414

[8]. Westley, K. (2021). Satellite-derived bathymetry for maritime archaeology: Testing its effectiveness at two ancient harbours in the Eastern Mediterranean. Journal of Archaeological Science: Reports, 38, 103030. https://doi.org/10.1016/j.jasrep.2021.103030

[9]. Lyzenga, D. R., Malinas, N. P., \& Tanis, F. J. (2006). Multispectral bathymetry using a simple physically based algorithm. IEEE Transactions on Geoscience and Remote Sensing, 44(8), 2251-2259. https://doi.org/10.1109/TGRS.2006.872909
[10]. Stumpf, R. P., Holderied, K., \& Sinclair, M. (2003). Determination of water depth with high-resolution satellite imagery over variable bottom types. Limnology and Oceanography, 48(1part2), 547-556. https://doi.org/10.4319/10.2003.48.1 part 2.0547

[11]. Van Hengel, W., \& Spitzer, D. (1991). Multitemporal water depth mapping by means of Landsat TM. International Journal of Remote Sensing, 12(4), 703-712.

https://doi.org/10.1080/01431169108929687

[12]. Pacheco, A., Horta, J., Loureiro, C., \& Ferreira, Ó. (2015). Retrieval of nearshore bathymetry from Landsat 8 images: A tool for coastal monitoring in shallow waters. Remote Sensing of Environment, 159, 102-116. https://doi.org/10.1016/j.rse.2014.12.004

[13]. Jagalingam, P., Akshaya, B. J., \& Hegde, A. V. (2015). Bathymetry mapping using Landsat 8 satellite imagery. Procedia Engineering, 116, 560-566. https://doi.org/10.1016/j.proeng.2015.08.326

[14]. Arya, G. W., \& Santoso, A. I. (2016). Evaluasi Akurasi Ekstraksi Kedalaman Laut dengan Metode Lyzenga dan Modifikasinya Menggunakan Data Spot7 di Teluk Belangbelang Mamuju. Jurnal Ilmiah Geomatika, 22(1), 09-19. http://dx.doi.org/10.24895/JIG.2016.22-1.423

[15]. Setiawan, K. T., Suwargana, N., Ginting, D. N. B., Manessa, M. D. M., Anggraini, N., Adawiah, S. W., Julzarika, A., Surahman, S., Rosid, S., Supardjo, A. H. (2018). Estimasi Batimetri dari Data Spot 7 Studi Kasus Perairan Gili Matra Nusa Tenggara Barat. Jurnal Penginderaan Jauh dan Pengolahan Data Citra Digital Vol. 15 No. 2.

http://dx.doi.org/10.30536/j.pjpdcd.2018.v15.a3008

[16]. Sartika, D., Hartoko, A., Kurniawan. 2018. Analisis Data Batimetri Lapangan Dan Citra Landsat 8 OLI Di Perairan Selat Lepar Kabupaten Bangka Selatan (Analysis Batimetry Field And Batimetry Citra Landsat 8 Oli In Lepar Current Regency Of South Bangka). Saintek Perikanan : Indonesian Journal of Fisheries Science and Technology, vol. 13, no. 2, pp. 75-81. https://doi.org/10.14710/ijfst.13.2.75-81

[17]. Irwanto, D. (2018, September). Perkiraan batimetri perairan dangkal menggunakan Citra Landsat 8 . In Prosiding Seminar Nasional Kelautan dan Perikanan IV (pp. 1-12).

[18]. Sitepu, R. S., Saputro, S., \& Satriadi, A. (2017). Studi Sebaran Sedimen Dasar Di Teluk Krueng Raya Dan Sekitarnya. Journal of Oceanography, 6(4), 625632.

[19]. Cheng, C. L., \& Garg, G. (2014). Coefficient of determination for multiple measurement error models. Journal of Multivariate Analysis, 126, 137152. https://doi.org/10.1016/j.jmva.2014.01.006

[20]. Moore, D. S., Notz, W., \& Fligner, M. A. (2013). The basic practice of statistics (Vol. 32, p. 745). New York: WH Freeman. 